\title{
Mycosphere Essay 17 Arbuscular mycorrhizal symbiosis and drought tolerance in crop plants
}

\author{
Mathimaran $\mathrm{N}^{1,2}$, Mahaveer P Sharma ${ }^{3}$, Mohan Raju $\mathrm{B}^{4}$ and Bagyaraj DJ ${ }^{5^{*}}$
}

\author{
1 Department of Environmental Sciences - Botany, University of Basel, Hebelstrasse 1, 4056 -Basel, Switzerland, \\ Email: mathimaran.natarajan@unibas.ch \\ 2 Department of Soil Sciences, Research Institute of Organic Agriculture (FiBL), Ackerstrasse 113, Postfach 2195070 \\ Frick, Switzerland, Email: mathi.natarajan@fibl.ch \\ 3 ICAR -Indian Institute of Soybean Research, Khandwa Road, Indore - 452 001, M.P., India, Email: \\ mahaveer620@gmail.com \\ 4 Department of Crop Physiology, University of Agricultural Sciences, GKVK campus, Bangalore - 560 065, India, \\ Email: bmohanraju@gmail.com \\ 5 Centre for Natural Biological Resources and Community Developemnt, 41RBI Colony Anand Nagar, Bangalore - \\ 560 024, India, Email: djbagyaraj@gmail.com
}

Mathimaran N, Mahaveer P Sharma, Mohan Raju B, Bagyaraj DJ 2017 - Mycosphere Essay 17 Arbuscular mycorrhizal symbiosis and drought tolerance in crop plants. Mycosphere 8(3) 361-376, Doi 10.5943/mycosphere/8/3/2

\begin{abstract}
Drought dramatically reduces crop yield, therefore remains as a major threat to food security. Overcoming drought by crop plants is a complex phenomenon - where plants find ways mainly through physiological adaptation. However, in nature, the plants rely also on microbes for mitigating the drought effects. Below ground association of plant roots with rhizosphere microorganisms for tolerating drought has been though established earlier, the exact mechanism is being understood only recently. The role of below ground microbes, particularly by the arbuscular mycorrhizal fungi (AMF), in drought tolerance by crop plants is currently a key research topic. The significance and highlights of the recent research as well as the past understanding of mechanisms by which crop plants tolerate drought through association of soil beneficial microbes, particularly with that of the AMF, is discussed in this review.
\end{abstract}

Keywords - Antioxidants - Mycorrhizal fungi - Osmotic adjustment - Plant water relations Water stress

\section{Introduction}

Drought, induced by climate -change or depletion of ground water, is arguably the major agent limiting the crop growth and productivity, and poses biggest challenge for the global food security (Rajkumar et al. 2013). Through a series of morphological, physiological, biochemical and molecular changes, drought could affect the growth and productivity and hence, forms an important abiotic stress (Wang et al. 2003). Drought tolerance in crop plants is multi -dimensional ranging from morphological, physiological to molecular level (Lopes et al. 2011). Although plants could adapt a number of strategies to alleviate/ overcome stress effects, mycorrhizal association is emerging as one of the efficient ways to combat stress effects and hence makes the plants to grow 
better under drought environment (Gianinazzi et al. 2010). In fact, several studies have shown the importance of use of microbial inoculants, especially the AMF in alleviating drought stress in crop plants (Zoppellari et al. 2014).

\section{Arbuscular Mycorrhizal Fungi}

AMF belong to the phylum Glomeromycota, which has a single class Glomeromycetes with 4 orders Glomerales, Diversisporales, Paraglomerales and Archaeosporales. The commonly occurring genera of AMF are Glomus, Gigaspora, Scutellospora, Acaulospora and Entrophospora. AMF symbiosis is unique as part of the fungus (intraradical hyphae, arbuscules and vesicles) is inside the root and part of the fungus (extraradical hyphae and extramatricular chlamydospores) is outside the root in soil. These fungi are obligate symbionts and have not been cultured on nutrient media. AMF though are not host specific but exhibit host preference, thus enabling to screen and select an efficient AMF for inoculating a particular crop (Bagyaraj 2014). The increased growth of mycorrhizal plants is favoured in soils with low to moderate fertility. Greater soil exploration by mycorrhizal roots as a means of increasing the uptake of diffusion limited nutrients like $\mathrm{P}, \mathrm{Zn}, \mathrm{Cu}$, etc. is well established. The other beneficial effects are their role in the biological control of root pathogens, hormone production and greater ability to withstand water stress (Bagyaraj et al. 2015).

In nature, nearly $70-90 \%$ of the terrestrial plants have an interaction with the root symbionts to ensure sufficient nutrient supply and alleviate environmental stresses (Zhu et al. 2010). Both plants and AMF are known to affect each other implying that both partners are highly interlinked in influencing ecosystem processes (Mathimaran et al. 2007). Drought tolerance by plants via AMF is considered to be a cumulative effect of physical, nutritional, physiological and cellular processes (Ruiz -Lozano 2003).

\section{Physical features of AMF and drought tolerance}

Many mechanisms of drought tolerance are related to the physiology of the host plant, but some are also related to the extraradical AMF mycelia. The AMF hyphae can absorb water, as demonstrated by the difference in transpiration flux in AM -clover and leek plants with and without extraradical hyphae (Hardie 1985). Extraradical AMF hyphae may also improve the capacity of the root system to extract soil water by giving it access to micropore water. Because of their smaller diameter, hyphae can enter pores that are too small for root hairs to access. Furthermore, AMF hyphae proliferate well beyond the limit of root hairs giving plants access to more water -filled pores. The extraradical hyphae can transport water to the root at the rate of 0.28 ng per second per entry point, a level which is enough to modify plant water relations (Allen 1982). According to Faber et al. (1991), the rate of water transport by AMF hyphae crossing air gaps between the compartments ranges from $375-760 \mathrm{nl} \mathrm{H}_{2} \mathrm{O} \mathrm{h}^{-1}$. This clearly suggests the role of extraradical hyphae in transporting water.

AMF mycelia could also improve soil water -holding capacity through enhanced soil aggregation (Auge et al. 2001). Improved soil structure generally improves soil moisture retention properties and as a result, mycorrhizal soil may hold more water at a given soil water potential than non -mycorrhizal soil and thus mycorrhizal plants will have access to a larger reservoir of soil water. Marulanda et al. (2003) have observed that the enhanced ability of mycorrhizal plants to absorb water is related to the length of their extraradical mycelia. For example, Funneliformis mosseae (=Glomus mosseae) colonized lettuce had utilized $0.6 \%$ (volumetric) of soil water, while Rhizophagus intraradices (=Glomus intraradices) colonized lettuce plants of the same size used $0.95 \%$ of soil water. In association with symbiotic AMF, plants could explore larger volumes of soil to absorb water and nutrients thereby impart stress tolerance to the plants (Smith et al. 2009).

\section{Physiological features of AMF and drought tolerance}

At physiological level, AMF regulate the plant nutrient uptake, stomatal conductance, leaf water potential, photosynthesis and transpiration rate (Li et al. 2014, Yang et al. 2014). Besides this, symbiotic association could also induce production of growth promoting hormones, anti - 
oxidative enzymes (Zhu et al. 2011a), improve plant root architecture (Wu et al. 2012) and soil properties. Taken together, all these events help the plants to produce significantly higher yields under stressful conditions.

Various mechanisms both at physiological and at molecular level by which the AMF regulate the plant drought response have been reported (Auge 2004, Suriyagoda et al. 2014). It appears that AMF regulates the root hydraulic conductance by modifying potassium ion levels (El Mesbahi et al. 2012). Furthermore, AMF may also regulate the hydraulic properties of plants through regulation of plasma -membrane intrinsic proteins in combination with phytohormones ( Ruiz -Lozano et al. 2009). A recent finding indicates that AMF play a key role in modifications of root hairs consequently helping the plants to overcome the drought (Li et al. 2014). Besides helping the plants to explore larger volumes of soils for absorbing more water, AMF help the plants to maintain high relative water content (RWC) of the leaf, improves water use efficiency (WUE) (Beltrano et al. 2003; Meddich et al. 2015), increase leaf area, delay senescence (Beltrano and Ronco 2008) and maintain ion balance (Giri et al. 2007). Furthermore, association also makes the plants to have greater osmotic adjustment through accumulation of osmolytes and more specifically, the proline. In addition, through increased anti-oxidative activity, the levels of reactive oxygen species (ROS) is regulated in plants that are associated with AMF leading to reduced oxidative stress damage (Zhu et al. 2011a).

One of the key mechanisms by which AMF alleviate drought stress in plants is through regulating plant gene expression, such as aquaporins (Barzana et al. 2014), as well as through regulating physiological and biochemical processes (Zhu et al. 2011b). Recent evidence suggests that AMF not only regulate the plant aquaporin gene expression but also regulate its own aquaporin genes which in turn help the plants to overcome drought (Li et al. 2013a, b). Recently, Li et al (2013a) have observed that in the arbuscule enriched cortical cells and extraradical hyphae of maize roots, the expression of two functional aquaporin genes from AMF i.e., GintAQPF1and GintAQPF2 were found to enhance greatly under drought stress. Further, their research provided molecular evidence for the transport of water to plants via AMF hyphae under osmotic stress thereby enhancing plant drought tolerance. These evidences clearly showed the role of mycorrhizal fungi in imparting stress tolerance to plants.

\section{AMF association on plant water relations}

Maintenance of tissue water status is an important aspect for improved metabolic activities of the tissues under stressful environment. Stress tolerant varieties/ genotypes through a number of strategies could maintain high tissue water status and thereby stress effect is not felt by the plants. Therefore, maintenance of tissue water status has lot of relevance for improved growth and productivity of the plants under stressful environments. In fact, maintenance of leaf water status is an important trait to alleviate the effect of drought stress. In this direction, the AMF offer protection to the plants where, they could help the plants to maintain tissue water status under stressful environments. A large number of experimental evidences indicated that, the RWC and water potential of the leaves of mycorrhizal plants are significantly more than the non - -mycorrhizal plants. For instance, Zhu et al. (2012) have reported that, the RWC and leaf water potential of the AMF plants were significantly higher than non -AM maize plants especially under drought stress condition. Improved leaf water status in AM plants was also reported by Colla et al. (2008) in Zucchini leaves and in maize leaves by Sheng et al. (2008) to indicate its relevance under stress conditions. The improved tissue water status in AM plants has been attributed to increased water uptake (Jiang and Huanz, 2003), change in root structure and enhanced root activity (Berta et al. 1990). AMF colonization improves the exploitation of soil water below permanent wilting point (Franson et al. 1991). This is probably due to increased capacity of roots to scavenge water in dry soils resulting in less stress to roots and foliage (Daun et al. 1996).

Besides maintenance of tissue water status of plants, fungal association also benefits the plants by increasing their water use efficiency (WUE). For example in maize, Zhu et al. (2012) have shown improved WUE and attributed this to increased water and mineral uptake from the soil 
leading to better growth of plants and hence, increased WUE. Increased WUE of AM -seedlings was also noticed by Yang et al. (2014) in black locust (Robinia pseudoacacia L.) seedlings. Therefore, the available information clearly indicated the role of AMF in imparting stress tolerance to the plants besides improving their WUE as well.

\section{AMF association on osmotic adjustment}

Osmotic adjustment is one of the important drought adaptive traits, which has lot of relevance in maintaining the tissue water status in plants grown under stressful conditions. When plants are subjected to stress treatment, they produce significantly high amount of several osmolytes and most notable among them are proline, glycine, betaine and sugar alcohols. In several systems, it has been reported that the mycorrhizal association further enhances osmolytes accumulation in plants upon stress. This indicates the relevance of AMF in facilitating the plants to go for osmotic adjustment for maintaining better water relations of the plant tissues. Kaya et al. (2009) have reported that the maize plants in association with AMF accumulated significantly high amount of proline under salt stress conditions. Similarly in bell pepper, the proline content was found to be increased by 3 folds in leaves and 2 folds in roots that suggest the role of AMF in enhancing proline accumulation in different tissues facilitating plants to maintain tissue water status (Beltrano et al. 2013). Greater drought tolerance in the form of effective osmotic adjustment resulting from higher accumulation of proline in AM inoculated plants has also been reported by several others as well (Azcon et al. 1996). Zhu et al. (2011a) have noticed around 56\% increase in proline level with improved osmotic adjustment in leaves of mycorrhizal plants than non mycorrhizal plants of maize. Due to improved osmotic adjustment, the tissue water status was found to be higher in fungal associated plants and therefore, these plants showed greater membrane stability under stress leading to reduced electrolytes leakage. This improvement in membrane stability has also been attributed to $\mathrm{P}$ induced changes in membrane phospholipids levels and also in permeability properties (Evelin et al. 2011).

Higher osmotic adjustment capacity is a characteristic feature of drought tolerance (Auge 2001) as it allows the cell to maintain turgor and turgor dependent processes like stomatal opening, cellular expansion, growth, photosynthesis as well as keeping the water potential gradient favorable for water entry into the plant root (Ruiz - Lozano et al. 2003). Trehalose, a nonreducing disaccharide, has been found to play a physiological role as drought stress protectant. Trehalose accumulation in an organism protects the cell by stabilizing cell structures and enables protein to maintain its native confirmation under drought stress. Garcia et al. (2005) have reported that trehalose occurs in plants colonized by symbiotic organisms like AMF and rhizobia. Trehalose accumulation in mycorrhizal roots inoculated with either $F$. mosseae or $G$. versiforme was reported by Schubert et al. (1992) as well. During the recovery from certain stresses like heat shock and chemical treatment (arsenate) the role of trehalose accumulation in AMF has also been observed (Ocon et al. 2007). However, the role of trehalose induced by AMF in imparting drought tolerance in crop plants needs more investigation.

\section{AMF association on the activity of antioxidant system}

When plants are subjected to stress, reactive oxygen species (ROS) are generated in large quantity causing oxidative stress damage to the plants. Reactive oxygen species and other free radicals are toxic molecules capable of causing oxidative damage to the lipids, DNA and proteins (Miller et al. 2010). If these molecules are not managed properly, they cause significant damage to the membranes and cause catastrophic effects on cell metabolism. Therefore, efficient quenching of ROS and free radicals is very crucial for survival and cell metabolism under stress conditions. Stress tolerant plants could manage the ROS and other free radicals through higher activity of antioxidant system (Zhu et al. 2011a).

Mycorrhizal association has been shown to have significantly higher antioxidant activity in several systems. For instance in maize, Zhu et al. (2011b) have reported low melondialdehyde (MDA) content in mycorrhizal plants under drought stress which was $17.50 \%$ lower than that of 
non -mycorrhizal plants. In several systems, MDA has been shown to damage the membranes and disrupting the cell metabolism. Therefore, low level of MDA observed in maize plants associated with AMF is an indication of positive effect of AMF on reducing the ROS level in plants. Such reduced level of MDA has also been reported by others in different plants (Porcel and Ruiz Lozano 2004, Wu et al. 2006a). These results perhaps support the argument that the mycorrhizal plants could tolerate the stress effects through reduced ROS levels under stress conditions.

Maintenance of low ROS or reduced oxidative damage in AM plants is also due to the enhanced activity of some of the antioxidant enzymes where, they convert the toxic molecules (ROS) into non -toxic or less toxic molecules. The level of antioxidant enzymes such as superoxide dismutase (SOD), catalase and peroxidase was found to be significantly high in mycorrhizal plants than non - mycorrhizal plants when grown under stressful environment (Porcell and Ruiz -Lozano 2004, Wu et al. 2006b, Khalafallah and Abo -Ghalia 2008). Inoculation with F. mosseae in strawberry under drought stress increased the activity of antioxidant enzymes like catalase (CAT), ascorbate peroxidase (APX), accumulation of free proline and soluble protein, and decreased the MDA content and plasma membrane conductivity (Baozhong et al. 2010). In drought stressed lettuce plants, F. mosseae increased the activity of SOD in shoot by $93 \%$ and G. deserticola by 128\% (Ruiz -Lozano et al. 1996). The ROS generated under stressful condition were quenched efficiently by the action of anti-oxidative enzymes and therefore, the level of ROS was found to be significantly low in AM plants. Besides antioxidant enzymes, the non -enzymatic system also helped to reduce the level of ROS in plants. For example, in the flowering plant cyclamen, higher levels of ascorbic acid and polyphenols besides APX and SOD were noticed in leaves, roots and tubers of stressed plants suggesting the role of non -antioxidant systems to deal with oxidative stress (Maya and Matsubara, 2013). Earlier studies also suggest that the mycorrhizal association helps the plants to overcome the oxidative stress damage and hence, the plants could continue to grow and produce without much of yield penalty under stress conditions. In general, AMF can affect the overall plant biomass through its role in $\mathrm{P}$ acquisition (Auge, 2001). Under stress conditions a diverse array of antioxidant enzymes is generated in response to ROS and free radicals which have an important role in drought tolerance of plants.

Besides direct influence, AMF also exert indirect effect by secreting the protein glomalin in soil which may be related to stress protection to plants. Rillig and Steinberg (2002) while studying glomalin using glass beads to study whether AMF are able to modify a sub -optimal growth condition found that despite having a smaller hyphal length in larger beads, higher amount of glomalin can be secreted in the small beads which were representing a non -aggregated soil. According to Gadkar and Rillig (2006), glomalin is a putative homolog of heat shock protein 60 (HSP60), as the protein (cross reactive to MAb32B11) from $R$. intraradices had 17 amino acid sequences similar to HSP60.

\section{AMF association on plant photosynthesis}

Photosynthesis is generally affected when plants are subjected to stressful environment. Due to reduced photosynthesis coupled with reduced leaf area, total carbon available for growth and productivity is less and therefore, significant yield reduction is encountered in stressed plants. Mycorrhizal association has been shown to increase the carbon fixation abilities of the plants. In a number of systems, higher photosynthetic rates have been reported when the plants are in association with AMF. For instance, in black locust, Yang et al. (2014) have observed high stomatal conductance, high transpiration rates and high photosynthetic rates with reduced internal $\mathrm{CO}_{2}$ concentration in fungal colonized plants than the non-colonized plants. Increased gas exchange parameters are not only seen under controlled condition but even in plants exposed to mild stress conditions. Such higher photosynthetic rate as a consequence of fungal association has also been reported by Zhu et al. (2012). They observed high photosynthetic and transpiration rates in AMF colonized plants of maize than in non -colonized plants both under control and drought stress conditions. In these plants, the stomatal conductance was found to be significantly higher indicating the ability of the mycorrhizal plants to keep the stomata wide open to facilitate the 
exchange of gases both for transpiration and for photosynthesis (Subramanian et al. 1995). In one of the classical works, when non -mycorrhizal wheat plants and mycorrhizal ones inoculated with $R$. fasciculatus $(=G$. fasciculatum) were watered to soil saturation and then allowed to continue transpiring until the soil gets dried up, the stomata in non -mycorrhizal plants began to close at a leaf water potentials of $-1.8 \mathrm{MPa}$ and were closed after 4 days, while the mycorrhizal plants did not begin to close until potentials of -2.2 to $-2.7 \mathrm{MPa}$ were reached and were still transpiring after $6-7$ days (Allen and Boosalis, 1983). This again clearly indicates the role of mycorrhiza in allowing the plants to function even at low water potential. Higher photosynthetic rate, transpiration rate and high stomatal conductance coupled with low $\mathrm{Ci}$ (internal $\mathrm{CO}_{2}$ concentration) was also noticed by Sheng et al. (2008) in maize. Across different salinity stress levels, the mycorrhizal plants ended up in exhibiting high photosynthetic and transpiration rates to indicate that the association is indeed helping the plants to fix more carbon at any given point of time. Besides higher photosynthetic rates, mycorrhizal association would also impart greater tolerance to the plants similar to that of Abscisic acid (ABA). In one such study, Aroca et al. (2008) have shown that AM plants fed with exogenous ABA produced higher shoot biomass during drought stress and recovery by balancing the leaf transpiration and root water uptake indicating the role of AMF in allowing the plants to grow even under drought stress conditions.

Although photosynthetic rate increased in AM plants the stomatal conductance and transpiration rate did not show significant difference compared to that of non -AM plants in clover (Wright et al. 1998). Improved photosynthetic rate has also been reported in other species such as citrus, soybean and barley (Brown and Bethlenfalvay 1988). However, in contrast to this, no stimulation of photosynthesis in response to mycorrhizal colonization was noticed in a few other systems to indicate that the response is species/ crop specific (Peng et al. 1993).

Higher photosynthetic rates coupled with high stomatal conductance and high transpiration and low Ci observed in most AM plants is attributed to enhanced water uptake and maintenance of high tissue water status (high RWC and leaf water potential) followed by high WUE in these plants. Uptake and movement of sufficient water to the evaporative surface helped the plants to maintain guard cell turgidity leading to opening of stomata for a gaseous exchange process (Nelsen and Safir 1982). Through the opened stomata, more $\mathrm{CO}_{2}$ enters the plants thereby the photosynthesis is improved in such plants (Zhu et al. 2011b). As the AM plant has the ability to mine water from soil, it could supply the water requirement of the evaporative surface and thus, the transpiration rate was also found to be significantly higher in fungal colonized plants (Roumet et al. 2006).

Higher rates of photosynthesis in AM plants could also be attributed to chlorophyll content of the leaves. The AM plants have shown to have higher chlorophyll content compared to non -AM plants. This observation has been made by several workers in different systems (Auge 2001, Colla et al. 2008). In pepper for instance, the chlorophyll content was shown to be increased by $15-25 \%$ to indicate the relevance of mycorrhizal association in increasing the pigment content in the leaves (Beltrano et al. 2013). Apart from increasing the chlorophyll content, the mycorrhizal association somehow protects the chlorophyll pigment from degradation under stressful conditions (Colla et al. 2008) and therefore it is clear that the fungal association is indeed beneficial to plants as it protects the plants from stress effects.

Increased photosynthetic rates upon fungal colonization are also attributed to the cost imposed on the plant's carbon economy by the growth of fungus. It is expected that the cost incurred towards the fungus is met out through increased carbon fixation by the plants (Wright et al. 1998). Through this strategy, the cost imposed on plant's carbon economy is reduced or even eliminated. This is true because, no evidence of biomass gain for additional allocation of carbon to the plant and therefore, it is suggested that, the additional carbon was allocated to the fungus to meet out the cost of growth of fungus. However, although mycorrhizal association is a costly affair for plants as the fungus drains out some amount of carbon from the plant, it is still beneficial as it offers lot of other benefits to the plants. 
Under stress it so happens that the structure and function of PSII reaction center gets damaged leading to disruption of electron transport. However, the mycorrhizal association has been found to mitigate the adverse influence of drought stress on PSII reaction center and photosynthetic efficiency (Baker 2008). This is evident from the fact that the dark adapted (Fv/Fm) and light adapted (Fv1/Fv1) maximum quantum yield as well as non -photochemical quenching (NPQ) parameters which were found to be higher in mycorrhizal plants than non -mycorrhizal plants (Sheng et al. 2008). Thus, PSII system is protected under stress condition (Maxwell and Johnson, 2000). Overall, it can be inferred that the mycorrhizal association could improve both the photochemistry and biochemistry of the plants to fix more carbon especially under stressful conditions (Zhu et al. 2012).

\section{Mycorrhizal association imparting drought tolerance in crop plants}

Mycorrhizal association improving drought tolerance of agronomically important crop plants has been reported by earlier workers in crops like wheat, soybean, onion, capsicum, maize, barley, cotton, etc. (Beltrano et al. 2013, Maya and Mastbara 2013). Improved growth and development of mycorrhizal plants especially in stressful environment is partly attributed to better water status of the leaf tissues (Colla et al. 2008), improved abilities to absorb nutrients from soil, higher root hydraulic conductivity and high photosynthetic rates of mycorrhizal plants (Yang et al. 2014). Therefore, it is evident that the mycorrhizal fungal association offers a number of benefits to the plants. Although the association is costly to the plant as it has to shell down some amount of carbon to the fungi, still the benefits derived in terms of protecting the plants under stress is much more than what the plant is losing. Under the conditions of water deficit, the external mycelium of $R$. intraradices may have a direct role in transport of considerable amount of nitrogen in the form of $\mathrm{NO}_{3}$ as observed in maize plants where roots also had higher glutathione reductase activity and $\mathrm{P}$ -status in host plants (Subramanian and Charest 1999).

Simpson and Daft (1990) reported that mycorrhizal colonization levels in maize and sorghum were increased by drought while spore production was reduced. Although, in general, drought affects the AMF colonization negatively (Ryan and Ash 1996), in wheat AMF has been shown to alleviate the drought stress and increase yield mainly through improved nutrient uptake (Al -Karaki et al. 2004). Claroideoglomus claroideum (=Glomus claroideum) seems to play a key role in imparting drought tolerance in wheat by improved chlorophyll content and cell membrane permeability (Beltrano and Ronco 2008). Effects of AMF on drought alleviation seem to also differ among genotypes of wheat ( $\mathrm{Al}$-Karaki and $\mathrm{Al}$-Raddad, 1997). In maize, drought tolerance was due to the reduction of MDA mediated by AMF (Zhu et al. 2011a). In another instance, it was shown that root hydraulic properties in maize plants were affected by AMF inoculation in the presence of higher potassium levels (El-Mesbahi et al. 2012). At the molecular level it was shown that, AMF up -regulates the aquaporin genes and consequently may play a key role in improved water uptake in maize plants ( $\mathrm{Li}$ and Chen 2012).

Various horticultural crops have been shown to tolerate drought via AMF. For example, $\mathrm{Wu}$ et al. (2013) have shown that the AMF inoculated citrus exhibited higher drought tolerance than the non -AMF citrus. In lettuce, an important vegetable crop in Europe, the AMF association promoted secondary metabolite production thereby making the plants to withstand abiotic stress (Baslam and Goicoechea 2012). AMF has been shown to be associated with date palms indicating possible role of the AMF in withstanding droughts of deserts (Symanczik et al. 2014). In tomato, it was observed that the AMF help to improve the plant nutrient, fruit quality status and drought tolerance (Subramanian et al. 2006). In capsicum, the improved fruit weight, fruit size and carotenoids were attributed to AMF association (Mena -Violante et al. 2006). Similarly, in papaya hybrids, higher yields were achieved even under drought condition in the presence of AMF (Elder et al. 2002).

Inoculation of tomato plants with $R$. intraradices resulted in improved nutritional status, increased shoot dry matter, fruits and flowers with higher quantities of ascorbic acid and total soluble solids (Subramanian et al. 2006). Ballesteros -Almanza et al. (2010) observed that 
inoculation of common bean with AMF imparted drought tolerance by improving intraradical and extraradical hyphae, arbuscule development, and succinate dehydrogenase and alkaline phosphatase activity in root system. The list of AMF conferring drought tolerance on different crop species is given in table 1.

\section{Selection of AMF to Drought Tolerance}

In order to maintain plant soil equilibrium the selection of suitable AMF species is of utmost importance (Ruiz - Lozano et al. 1995). Under the conditions of drought in AMF inoculated rose plants, the improvement in water status observed was more in case of $R$. intraradices than $G$. deserticola (Auge et al. 1987). Marulanda et al. (2007) while performing comparative studies on four native drought tolerant (two autochthonous) and drought sensitive (two allochthonous) $R$. intraradices and $F$. mosseae in lavender plant found that the two autochthonous strains of $R$. intraradices and $F$. mosseae produced a higher root biomass, increased root growth, efficiently absorbed $\mathrm{N}$ and $\mathrm{K}$, increased water content and decreased antioxidant compounds. Better osmotic adjustment and plant tolerance against water stress after inoculation of Erythrina variegate with $F$. mosseae was reported by Manoharan et al. (2010). Inoculation of F. mosseae, G. versiforme and $R$. diaphanum $(=G$. diaphanum) in citrus under drought stress apart from enhancing plant growth also showed a positive correlation between the Bradford reactive soil protein concentration, soil hyphal length densities and water stable aggregates $(>2 \mathrm{~mm}, 1-2 \mathrm{~mm}$ and $>0.25 \mathrm{~mm}$ ) indicating an improvement in soil structure (Wu et al. 2007).

Under drought conditions, G. deserticola was found to benefit rosemary in terms of plant water status, enhanced water uptake, root hydraulic conductivity, increased photosynthetic activity and overall stimulation of plant growth in terms of aerial biomass (Sanchez -Blanco et al. 2004). Ruiz -Lozano et al. (1995) found G. deserticola to be the most effective species for increasing drought tolerance as it stimulated physiological parameters, enhanced water use efficiency and showed highest mycorrhizal root colonization. While studying the effect of AM inoculation on stomatal conductance to water vapor under drought conditions G. deserticola, Claroideoglomus etunicatum $(=G$. etunicatum) and Funneliformis sp. were found to have larger effects on dicotyledonous hosts than monocotyledons (Auge et al. 2014).

$\mathrm{Wu}$ et al. (2006b) on inoculating tangerine with $G$. versiforme observed a significant stimulation of plant growth and biomass, where inoculated seedlings had higher leaf water potential, transpiration rates, photosynthetic rate, stomatal conductance, relative leaf water content and lower leaf temperature. Inoculated plants also had higher non -structural carbohydrates, $\mathrm{K}^{+}$, $\mathrm{Ca}^{+}$and $\mathrm{Mg}^{+}$resulting in better osmotic adjustment. An increase in wheat drought tolerance was observed after inoculation with Rhizophagus fasciculatus than $F$. mosseae (Allen and Boosalis 1983). Under different levels of drought stress, F. constrictum ( $=G$. constrictum) was found to have positive impacts on all growth parameters (plant growth, $\mathrm{P}$ uptake and productivity) of marigold with stimulation of photosynthetic pigments and carotene in flowers. The total pigments were $60 \%$ higher in mycorrhizal plants compared to non -mycorrhizal plants (Asrar and Elhindi 2011). Marulanda et al. (2003) observed that AMF enhanced the rate of plant water uptake from soil where every fungal species differs from each other in the amount of external mycelium produced and also in the frequency of root colonization in terms of live and active fungal structures. They reported that $0.6 \%$ (volumetric) of soil water was used by $F$. mosseae - colonized lettuce, while $0.95 \%$ of soil water was used by $R$. intraradices colonized lettuce plants of the same size.

\section{Mechanisms of drought tolerance in plants via AMF and PGPR interactions}

Plant growth promoting rhizomicroorganisms (PGPR) promote plant growth and improve productivity. PGPR operate through either direct or indirect mechanisms or a combination of both. Direct mechanisms of plant growth promotion include the secretion of plant growth promoting metabolites like indole acetic acid (IAA), cytokinins, gibberellins, etc. and facilitating the uptake of essential nutrients (N, P, Fe, Zn, etc.) from the atmospheric air and soil. Indirect promotion of the plant growth occurs when PGPR lessen or prevent the deleterious effect of phytopathogenic 
organisms by the production of antibiotics, siderophores, hydrogen cyanide (HCN), etc (Hemlata Chauhan et al. 2015). The mechanism by which AMF alleviate drought stress in plants in the presence of PGPR is not fully understood. However, studies indicate that the PGPR may involve indirectly by mobilizing the nutrients, particularly the phosphorus, and transferring to plants via the AMF hyphae (Alguacil et al. 2009). On the other hand, the PGPR may also involve directly through plant hormonal regulation by producing metabolites such as 1 -aminocyclopropane -1 carboxylate (ACC) deaminase (Barnawal et al. 2013). Under elevated $\mathrm{CO}_{2}$ levels the PGPR alone or AMF -PGPR combination seem to improve the drought tolerance in plants by increasing the soil aggregates (Kohler et al. 2009, Minakshi Grover et al. 2015). Panwar (1993) studied the response of wheat to inoculation with the AMF $R$. fasciculatus and the nitrogen fixing bacterium Azospirillum brasilense under different stress conditions. The total chlorophyll content and nitrate reductase activity increased with reduced ion leakage from the leaves when the plants were inoculated with both the organisms compared to inoculation with a single organism. Further, dual inoculation also resulted in higher biomass and grain yield under water stress conditions. This reiterates the importance of combining useful microbes to improve the stress tolerance besides improving the plant productivity. In general, drought tolerance in plants seems to be better facilitated by consortium of AMF and PGPR originating from a drought environment compared to those plants inoculated with commercial consortia (Zoppellari et al. 2014).

There have been several studies on the tripartite symbiotic association with legumes Rhizobium and AMF (Valdenegro et al. 2001, Mortimer et al. 2013). However, AMF -Rhizobium interaction for alleviating drought stress in legume plants has not been well studied (Ide Franzini et al. 2010). Positive interactions of Rhizobium and AMF have been shown to improve the plant stress (Tarafdar and Rao, 1997), although it appears that the outcome of beneficial effect of AMF Rhizobium interaction may depend on the soil nutrient and moisture status as well as plant variety (Ide Franzini et al. 2010).

The role of the AMF, F. mosseae in minimizing the adverse effects of drought induced premature nodule senescence where it exerted positive effects on nitrogen fixation, leghaemoglobin and protein contents, and overall protection against oxidative damage to lipids and proteins in nodules has been reported (Ruiz Lozano et al. 2001). Porcel et al. (2003) have attributed the decreased oxidative damage to biomolecules involved in premature nodule senescence to higher glutathione reductase activity in the nodules of soybean plants colonized by $F$. mosseae (Zhu et al. 1997).

\section{Conclusion and future perspectives}

Water is undisputedly the major factor for the declining food production in many parts of the world, particularly in the arid and semi -arid regions. Consequently, the world is now being challenged to produce "more crop per drop" of water. Therefore, in recent years there are increasing number of studies to understand the mechanism by which plants alleviate drought stress, particularly via the AMF, a crucial symbiont for most crop plants in the terrestrial ecoystem. Although several studies have started to unravel the molecular mechanisms of the interplay between the AMF - plant symbiosis, we are yet to completely understand the exact mechanism about the water and nutrient uptake by plants via the AMF especially under drought condition. For example, we know very little about the mechanism by which the plants roots redistribute the water taken (hydraulically lifted water) from a moist to dry region in order to forage the nutrients via the AMF. There is an urgent need for understanding this mechanism and to design appropriate plant AMF combination for better use of the natural resources, particularly the water, in arid and semi arid regions of the world. Future research, therefore, should be based on the holistic approaches involving multi - disciplinary sciences, such as plant and fungal physiology, soil and molecular biology, for better understanding of the processes in plant -AMF -soil continuum. 
Table 1 Examples of AMF conferring drought tolerance in crop plants

\begin{tabular}{|c|c|c|c|c|}
\hline Species & Crop & Stress & Mechanism & Reference \\
\hline $\begin{array}{l}\text {-laroideoglomus } \\
\text { etunicatum }\end{array}$ & Maize & $\begin{array}{l}\text { High } \\
\text { temperature }\end{array}$ & $\begin{array}{l}\text { Reduced membrane lipid } \\
\text { peroxidation, membrane } \\
\text { permeability and increased } \\
\text { accumulation of osmotic } \\
\text { adjustment compounds and } \\
\text { antioxidant activity. }\end{array}$ & Zhu et al. (2010) \\
\hline 3lomus versiforme & $\begin{array}{l}\text { Citrus (Citrus } \\
\text { tangerine) }\end{array}$ & Drought & $\begin{array}{l}\text { Higher activities of catalase } \\
\text { (CAT), ascorbate peroxidase } \\
\text { (APX), superoxide dismutase } \\
\text { (SOD) }\end{array}$ & Wu et al. (2006b) \\
\hline${ }^{7}$ unneliformis mosseae & $\begin{array}{l}\text { Maize } \quad(Z e a \\
\text { mays })\end{array}$ & Drought & $\begin{array}{l}\text { Accumulation of amino acids } \\
\text { and imino acids, remarkable } \\
\text { increase in trehalose content } \\
\text { and higher trehalase activity }\end{array}$ & $\begin{array}{l}\text { Schellenbaum, } \\
\text { (1998) }\end{array}$ \\
\hline $\begin{array}{l}\text { unneliformis mosseae } \\
\text { and } \\
\text { Zlaroideoglomus } \\
\text { etunicatum }\end{array}$ & $\begin{array}{l}\text { Wheat } \\
\text { (Triticum } \\
\text { asetivum) }\end{array}$ & Drought & $\begin{array}{l}\text { Higher biomass and higher } \\
\text { grain yields, shoot } \mathrm{P} \text { and Fe } \\
\text { concentration in mycorrhizal } \\
\text { plants }\end{array}$ & $\begin{array}{l}\text { Al -karaki et al. } \\
(2004)\end{array}$ \\
\hline Ilomus spp. & $\begin{array}{l}\text { Wheat } \\
\text { (Triticum } \\
\text { asetivum) }\end{array}$ & Water Stress & $\begin{array}{l}\text { Mycorrhiza increased the } \\
\text { content of free amino acids, } \\
\text { proline, total soluble and } \\
\text { crude protein, total } \\
\text { carbohydrate, total soluble } \\
\text { and insoluble sugars, and } \\
\text { enhanced the activity of } \\
\text { antioxidant enzymes like } \\
\text { peroxidase (POX) and } \\
\text { catalase (CAT). }\end{array}$ & $\begin{array}{l}\text { Khalafallah } \quad \text { and } \\
\text { Abo } \quad \text { Ghalia } \\
(2008)\end{array}$ \\
\hline $\begin{array}{l}\text { Rhizophagus } \\
\text { intraradices }\end{array}$ & $\begin{array}{l}\text { Sorghum } \\
\text { (Sorghum } \\
\text { bicolor) }\end{array}$ & Drought & $\begin{array}{l}\text { Mycorrhiza minimized the } \\
\text { adverse effect of drought and } \\
\text { increased the grain yield by } \\
17.8 \%\end{array}$ & $\begin{array}{l}\text { Alizadeh et al. } \\
(2011)\end{array}$ \\
\hline $\begin{array}{l}\text { Rhizophagus } \\
\text { intraradices }\end{array}$ & $\begin{array}{l}\text { Soybean } \\
\text { (Glycine max) }\end{array}$ & Drought & $\begin{array}{l}\text { Higher leaf water potential in } \\
\text { mycorrhizal plants, and } \\
\text { mycorrhiza protected the } \\
\text { plants against oxidative stress }\end{array}$ & $\begin{array}{ll}\text { Porcel and Ruiz - } \\
\text { Lozano } \\
\text { Meddich et al. } \\
(2015)\end{array}$ \\
\hline $\begin{array}{l}\text { unneliformis mosseae } \\
\text { Rhizophagus diaphanum } \\
\text { slomus versiforme }\end{array}$ & $\begin{array}{l}\text { Trifoliate } \\
\text { orange } \\
\text { (Poncirus } \\
\text { trifoliata) }\end{array}$ & Drought & $\begin{array}{l}\text { Higher plant growth and } \\
\text { biomass, acid and total } \\
\text { phosphatase activity, leaf and } \\
\text { root } \mathrm{P} \text { contents in drought } \\
\text { stressed mycorrhizal } \\
\text { seedlings particularly in } F \text {. } \\
\text { mosseae. }\end{array}$ & Wu et al. (2011) \\
\hline${ }^{7}$ unneliformis mosseae & Sunflower & Drought & $\begin{array}{l}\text { Inoculated plants produced } \\
\text { more dry matter, heavier } \\
\text { seeds and greater seed and oil } \\
\text { yields with } F \text {. mosseae. } \\
\text { Despite of reduction in } \mathrm{N} \\
\text { percentage due to drought, } \mathrm{N} \\
\text { percentage was higher in } \\
\text { inoculated plants compared } \\
\text { to control. }\end{array}$ & $\begin{array}{l}\text { Gholamhoseini et } \\
\text { al. (2013) }\end{array}$ \\
\hline Jlomus spp. & $\begin{array}{l}\text { Boswellia } \\
\text { papyrifera }\end{array}$ & $\begin{array}{l}\text { Pulsed water } \\
\text { availability } \\
\text { conditions }\end{array}$ & $\begin{array}{l}\text { Higher level of AM } \\
\text { colonization under irregular } \\
\text { precipitation regime where } \\
\text { mycorrhizal seedlings had } \\
\text { higher biomass, increased } \\
\text { transpiration, higher water }\end{array}$ & $\begin{array}{l}\text { Birhane et al. } \\
(2012)\end{array}$ \\
\hline
\end{tabular}




\begin{tabular}{|c|c|c|c|c|}
\hline Species & Crop & Stress & Mechanism & Reference \\
\hline & & & use efficiency & \\
\hline $\begin{array}{l}\text { unneliformis mosseae } \\
\text { Rhizophagus } \\
\text { intraradices }\end{array}$ & $\begin{array}{l}\text { Lettuce } \\
\text { (Lactuca } \\
\text { sativa.) }\end{array}$ & Water deficit & $\begin{array}{l}\text { Under water deficit, the } \\
\text { accumulation of potential } \\
\text { antioxidants } \\
\text { carotenoids, anthocyanins } \\
\text { and to a lesser extent } \\
\text { chlorophyll and phenolics) in } \\
\text { the leaves of mycorrhizal } \\
\text { lettuce plants were more. } \\
\text { Shoot biomass in AM lettuce } \\
\text { under moderate water deficit } \\
\text { was equal to well watered } \\
\text { AM plants. } \\
\text { Improved lettuce quality and } \\
\text { reduced irrigation without } \\
\text { affecting lettuce production }\end{array}$ & $\begin{array}{l}\text { Baslam and } \\
\text { Goicoechea (2011) }\end{array}$ \\
\hline
\end{tabular}

\section{References}

Alguacil MD, Kohler J, Caravaca F, Roldan A. 2009 - Differential effects of Pseudomonas mendocina and Glomus intraradices on lettuce plants physiological response and aquaporin PIP2 gene expression under elevated atmospheric $\mathrm{CO}_{2}$ and drought. Microbial Ecology 58, 942-951.

Alizadeh O, Zare M, Nasr AH. 2011 - Evaluation effect of mycorrhiza inoculation under drought stress condition on grain yield of sorghum (Sorghum bicolor). Advances in Environmental Biology 5, 2361-2364

Al -Karaki G, McMichael B, Zak J. 2004 - Field response of wheat to arbuscular mycorrhizal fungi and drought stress. Mycorrhiza 14, 263-269.

Al -Karaki GN, Al -Raddad A. 1997 - Effects of arbuscular mycorrhizal fungi and drought stress on growth and nutrient uptake of two wheat genotypes differing in drought resistance. Mycorrhiza 7, 83-88.

Allen MF, Boosalis MG. 1983 - Effects of two species of VA mycorrhizal fungi on drought tolerance of winter wheat. New Phytologist 93, 67-76.

Aroca R, Vernieri P, Ruiz -Lozano JM. 2008 - Mycorrhizal and non -mycorrhizal Lactuca sativa plants exhibit contrasting responses to exogenous ABA during drought stress and recovery. Journal of Experimental Botany 59, 2029-2041.

Asrar AWA, Elhindi KM. 2011 - Alleviation of drought stress of marigold (Tagetes erecta) plants by using arbuscular mycorrhizal fungi. Saudi Journal of Biological Sciences 18, 93-98.

Augé RM, Saxton AM, Toler HD. 2014 - Arbuscular mycorrhizal symbiosis alters stomatal conductance of host plants more under drought than under amply watered conditions: a meta -analysis. Mycorrhiza 25, 13-24.

Augé RM, Schekel, KA, Wample RL. 1987 - Rose leaf elasticity changes in response to drought acclimation and mycorrhizal colonization. Physiologia Plantarum 70, 175-182.

Auge RM. 2001 - Water relations, drought and vesicular -arbuscular mycorrhizal symbiosis. Mycorrhiza 11, 3-42.

Augé RM. 2004 - Arbuscular mycorrhizae and soil/plant water relations. Canadian Journal of Soil Science 84, 373-381.

Azcón R, Gomez M, Tobar R. 1996 - Physiological and nutritional responses by Lactuca sativa to nitrogen sources and mycorrhizal fungi under drought. Biology and Fertility of Soils 22, $156-161$.

Bagyaraj DJ, Sharma MP, Maiti D. 2015 - Phosphorus nutrition of crops through arbuscular mycorrhizal fungi. Current Science 108, 1288-1293.

Bagyaraj DJ. 2014 - Mycorrhizal fungi. Proceedings of Indian National Science Academy 80, 415428. 
Baker NR. 2008 - Chlorophyll fluorescence: a probe of photosynthesis in vivo. Annual Review of Plant Biology 59, 89-113.

Ballesteros -Almanza L, Altamirano -Hernandez J, Peña -Cabriales JJ, Santoyo G, Sanchez Yañez JM, Valencia -Cantero E, Macias -Rodriguez L, Lopez -Bucio J, Cardenas Navarro R, Farias -Rodriguez R. 2010 - Effect of co -inoculation with mycorrhiza and rhizobia on the nodule trehalose content of different bean genotypes. The Open Microbiolgy Journal 17, 83-92.

Baozhong Y, Wang Y, Liu P, Hu J, Zhen W. 2010 - Effects of vesicular - arbuscular mycorrhiza on the protective system in strawberry leaves under drought stress. Frontiers of Agriculture in China 4, 165-169.

Barnawal D, Maji D, Bharti N, Chanotiya CS, Kalra A. 2013 - ACC deaminase -containing Bacillus subtilis reduces stress ethylene -induced damage and improves mycorrhizal colonization and rhizobial nodulation in Trigonella foenum - graecum under drought stress. Journal of Plant Growth Regulators 32, 809-822.

Barzana G, Aroca R, Bienert GP, Chaumont F, Ruiz -Lozano JM. 2014 - New insights into the regulation of aquaporins by the arbuscular mycorrhizal symbiosis in maize plants under drought stress and possible implications for plant performance. Molecular Plant Microbe Interaction 27, 349-363.

Baslam M, Goicoechea N. 2012 -Water deficit improved the capacity of arbuscular mycorrhizal fungi (AMF) for inducing the accumulation of antioxidant compounds in lettuce leaves. Mycorrhiza 22, 347-359.

Beltrano J, Ronco MG, Salerno MI, Ruscitti M, Peluso O. 2003 - Respuesta de planta de trigo (Triticum aestivum L.) micorriza dasensituaciones de déficithídrico y de rehidratación del suelo. Revista de Ciencia y Tecnología 8, 1-7.

Beltrano J, Ronco, MG. 2008 - Improved tolerance of wheat plants (Triticum aestivum L.) to drought stress and rewatering by the arbuscular mycorrhizal fungus Glomus claroideum: Effect on growth and cell membrane stability. Brazilian Journal of Plant Physiology 20, 2937.

Beltrano J, Ruscitti1 M, Arango MC, Ronco M. 2013 - Effects of arbuscular mycorrhiza inoculation on plant growth, biological and physiological parameters and mineral nutrition in pepper grown under different salinity and $\mathrm{P}$ levels. Journal of Soil Science and Plant Nutrition 13, 123-141.

Berta G, Fusconi A, Trotta A, Scannerini S. 1990 - Morphogenetic modifications induced by the mycorrhizal fungus Glomus strain E3 in the root system of Allium porrum L. New Phytologist 114, 207-215.

Birhane E, Sterck FJ, Fetene M, Bongers F, Kuyper TW. 2012 - Arbuscular mycorrhizal fungi enhance photosynthesis, water use effeciency and growth of frankincense seedlings under pulsed water availability conditions. Oecologia 169, 895-904.

Brown MS, Bethlenfalvay GJ. 1988 - The Glycine-Glomus- Rhizobium symbiosis. VII. Photosynthetic nutrient use efficiency in nodulated, mycorrhizal soybeans. Plant Physiology 86, 1292-1297.

Colla G, Rouphael Y, Cardarelli M, Tullio M, Rivera CM and Rea E. 2008 - Alleviation of salt stress by arbuscular mycorrhizal in zucchini plants grown at low and high phosphorus concentration. Biology and Fertility of Soils 44, 501-509.

Duan X, Neuman DS, Reiber JM, Green CD, Saxton AM, Augé RM. 1996 - Mycorrhizal influence on hydraulic and hormonal factors implicated in the control of stomatal conductance during drought. Journal of Experimental Botany 47, 1541-1550.

Elder RJ, Reid DJ, Macleod WNB, Gillespie, RL. 2002 - Post -ratoon growth and yield of three hybrid papayas (Carica papaya L.) under mulched and bare -ground conditions. Australian Journal of Experimental Agriculture 42, 71-81. 
El-Mesbahi MN, Azcon R, Ruiz -Lozano JM, Aroca R. 2012 - Plant potassium content modifies the effects of arbuscular mycorrhizal symbiosis on root hydraulic properties in maize plants. Mycorrhiza 22, 555-564.

Evelin H, Giri B, Kapoor, R. 2011- Contribution of Glomus intraradices inoculation to nutrient acquisition and mitigation of ionic imbalance in $\mathrm{NaCl}$-stressed Trigonella foenum graecum. Mycorrhiza 22, 203-217.

Faber BA, Zasoski RJ, Munns DN. 1991 - A method for measuring hyphal nutrient and water uptake in mycorrhizal plants. Canadian Journal of Botany 69, 87-94.

Franson RL, Milford SB, Bethlenfalvay GJ. 1991 - The Glycine -Glomus -Bradyrhizobium symbiosis. XI. nodule gas exchange and efficiency as a function of soil and root water status in mycorrhizal soybean. Physiologia Plantarum 83, 476-482.

Gadkar V, Rillig MC. 2006 - The arbuscular mycorrhizal fungal protein glomalin is a putative homolog of heat shock protein 60. FEMS Microbiology Letters 263, 93-101.

García NA, Iribarne C, López M, Herrera-Cervera JA, Lluch C. 2005 - Physiological implications of trehalase from Phaseolus vulgaris root nodules: partial purification and characterization. Plant Physiology and Biochemistry 43, 355-361

Gholamhoseini M, Ghalavand A, Dolatabadian A, Jamshidi E. 2013 - Effects of arbuscular mycorrhizal inoculation on growth, yield, nutrient uptake and irrigation water productivity of sunflowers grown under drought stress. Agricultural Water Management 117, 106-114.

Gianinazzi S, Gollotte A, Binet M, Van Tuinen D, Redecker D, Wipf D. 2010 - Agroecology: the key role of arbuscular mycorrhizas in ecosystem services. Mycorrhiza 20, 519-530.

Giri B, Kapoor R, Mukerji KG. 2007 - Improved tolerance of Acacia nilotica to salt stress by arbuscular mycorrhiza, Glomus fasciculatum, may be partly related to elevated $\mathrm{K}+/ \mathrm{Na}+$ ratios in root and shoot tissues. Microbial Ecology 54, 753-760.

Hardie K. 1985 - The effect of removal of extraradical hyphae on water uptake by vesicular arbuscular mycorrhizal plants. New Phytologist 101, 677-684.

Hemlata Chauhan, Bagyaraj DJ, Selvakumar G, Sundaram SP. 2015 - Novel plant growth promoting rhizobacteria -Prospects and potential. Applied Soil Ecology 95, 38-53.

Ide Franzini V, Azcon R, Mendes FL, Aroca R. 2010 - Interactions between Glomus species and Rhizobium strains affect the nutritional physiology of drought -stressed legume hosts. Journal of Plant Physiology 167, 614-619.

Jiang XY, Huang Y. 2003 - Mechanism of contribution of mycorrhizal fungi to plant saline-alkali tolerance. Ecology and Environment 12, 353 -356.

Kaya C, Ashraf M, Sonmez O, Aydemir S, Tuna AL, Cullu MA. 2009 - The influence of arbuscular mycorrhizal colonization on key growth parameters and fruit yield of pepper plants grown at high salinity. Scientia Horticulturae 121, 1-6.

Khalafallah AA, Abo -Ghalia HH. 2008 - Effect of arbuscular mycorrhizal fungi on the metabolic products and activity of antioxidant system in wheat plants subjected to short -term water stress, followed by recovery at different growth stages. Journal of Applied Science and Research 4, 559-569.

Kohler J, Caravaca F, Alguacil MDM, Roldan A. 2009 - Elevated $\mathrm{CO}_{2}$ increases the effect of an arbuscular mycorrhizal fungus and a plant-growth-promoting rhizobacterium on structural stability of a semiarid agricultural soil under drought conditions. Soil Biology and Biochemistry 41, 1710-1716.

Li T, Chen BD. 2012 - Arbuscular mycorrhizal fungi improving drought tolerance of maize plants by up-regulation of aquaporin gene expressions in roots and the fungi themselves. Chinese Journal of Plant Ecology 36, 973-981.

Li T, Hu YJ, Hao ZP, Li H, Chen BD. 2013a - Aquaporin genes GintAQPF1 and GintAQPF2 from Glomus intraradices contribute to plant drought tolerance. Plant Signal Behaviour 8, e24030. 
Li T, Hu YJ, Hao ZP, Li H, Wang YS, Chen BD. 2013b - First cloning and characterization of two functional aquaporin genes from an arbuscular mycorrhizal fungus Glomus intraradices. New Phytologist 197, 617-630.

Li T, Lin G, Zhang X, Chen Y, Zhang S, Chen B. 2014 - Relative importance of an arbuscular mycorrhizal fungus (Rhizophagus intraradices) and root hairs in plant drought tolerance. Mycorrhiza 24, 595-602.

Lopes MS, Araus JL, van Heerden PDR, Foyer CH. 2011 - Enhancing drought tolerance in C4 crops. Journal of Experimental Botany 62, 3135-3153.

Marulanda A, Azcon R, Ruiz -Lozano JM. 2003 - Contribution of six arbuscular mycorrhizal fungal isolates to water uptake by Lactuca sativa plants under drought stress. Physiologia Plantarum 119, 526-533.

Marulanda A, Porcel R, Barea JM, Azcon R. 2007 - Drought tolerance and antioxidant activities in lavender plants colonized by native drought-tolerant or drought-sensitive Glomus species. Microbial Ecology 54, 543-552.

Mathimaran N, Ruh R, Jama B, Verchot L, Frossard E, Jansa J. 2007 - Impact of agricultural management on arbuscular mycorrhizal fungal communities in Kenyan ferralsol. Agriculture, Ecosystem and Environment 119, 22-32.

Maxwell K, Johnson GN. 2000 - Chlorophyll fluorescence- A practical guide. Journal of Experimental Botany 51, 659-668.

Maya MA, Matsubara Y. 2013 - Influence of arbuscular mycorrhiza on the growth and antioxidative activity in cyclamen under heat stress. Mycorrhiza 23, 381-390.

Meddich A, Jaiti F, Bourzik W, Asli AE, Hafidi M. 2015 - Use of mycorrhizal fungi as a strategy for improving the drought tolerance in date palm (Phoenix dactylifera). Scientia Horticulturae 192, 468-471.

Mena -Violante HG, Ocampo -Jimenez O, Dendooven L, Martinez -Soto G, Gonzalez -Castaneda J, Jr. Davies FT, Olalde -Portugal V. 2006 - Arbuscular mycorrhizal fungi enhance fruit growth and quality of chile ancho (Capsicum annuum L. cv San Luis) plants exposed to drought. Mycorrhiza 16, 261-267.

Miller G, Suzuki N, Ciftci -Yilmaz S, Mittler R. 2010 - Reactive oxygen species homeostasis and signaling during drought and salinity stresses. Plant, Cell \& Environment 33, 453-467.

Minakshi Grover, Maheswari M, Suseelendra Desai, Gopinath KA, Venkateswarlu B. 2015 Elevated $\mathrm{CO}_{2}$ : Plant associated microorganisms and carbon sequestration. Applied Soil Ecology 95, 73-85.

Mortimer PE, Le Roux MR, Perez -Fernandez MA, Benedito VA, Kleinert A, Xu JC, Valentine AJ. 2013 - The dual symbiosis between arbuscular mycorrhiza and nitrogen fixing bacteria benefits the growth and nutrition of the woody invasive legume Acacia cyclops under nutrient limiting conditions. Plant and Soil 366, 229-241.

Nelsen CE, Safir GR. 1982 - The water relations of well watered, mycorrhizal and non mycorrhizal onion plants. Journal of American Society of Horticultural Science 107, 271 274.

Ocon A, Hampp R, Requena N. 2007 - Trehalose turnover during abiotic stress in arbuscular mycorrhizal fungi. New Phytologist 174, 879-891.

Panwar JD. 1993 - Response of VAM and Azospirillum inoculation to water status and grain yield in wheat under water stress condition. Indian Journal of Plant Physiology 36, 41-43.

Peng S, Eissenstat DM, Graham JH, Williams K, Hodge NC. 1993 - Growth depression in mycorrhizal citrus at high phosphorus supply -analysis of carbon costs. Plant Physiology $10,1063-1071$.

Porcel R, Ruiz -Lozano JM. 2004 - Arbuscular mycorrhizal influence on leaf water potential, solute accumulation, and oxidative stress in soybean plants subjected to drought stress. Journal of Experimental Botany 55, 1743-1750.

Rajkumar M, Prasad MNV, Swaminathan S, Freitas H. 2013 - Climate change driven plant -metal -microbe interactions. Environment International 53, 74-86. 
Rilling MC, Steinberg PD. 2002 - Glomalin production by an arbuscular mycorrhizal fungus: a mechanism of habitat modification. Soil Biology and Biochemistry 34, 1371-1374.

Roumet C, Urcelay C and Diaz D. 2006 - Suites of root traits differ between annual and perennial species growing in the field. New Phytologist 170, 357-368.

Ruiz -Lozano JM, Alguacil MD, Barzana G, Vernieri P, Aroca R. 2009 - Exogenous ABA accentuates the differences in root hydraulic properties between mycorrhizal and non mycorrhizal maize plants through regulation of PIP aquaporins. Plant Molecular Biology 70, 565-579.

Ruiz -Lozano JM, Azcón R, Gómez M. 1995 - Effects of arbuscular - mycorrhizal Glomus species on drought tolerance: physiological and nutritional plant responses. Applied Environmental Microbiology 61, 456-460.

Ruiz -Lozano JM, Azcón R, Palma JM. 1996 - Superoxide dismutase activity in arbuscular mycorrhizal Lactuca sativa plants subjected to drought stress. New Phytologist 134, 327333.

Ruiz -Lozano JM, Collados C, Barea JM, Azcon R. 2001 - Arbuscular mycorrhizal symbiosis can alleviate drought - induced nodule senescence in soybean plant. New Phytologist 151, 493502.

Ruiz -Lozano JM, Marulanda A, Azco R. 2003 - Contribution of six arbuscular mycorrhizal fungal isolates to water uptake by Lactuca sativa plants under drought stress. Physiologia Plantarum 119, 526-533.

Ruiz -Lozano JM. 2003 - Arbuscular mycorrhizal symbiosis and alleviation of osmotic stress. New perspectives for molecular studies. Mycorrhiza 13, 309-317.

Ryan MH, Ash JE. 1996 - Colonisation of wheat in southern New South Wales by vesicular arbuscular mycorrhizal fungi is significantly reduced by drought. Australian Journal of Experimental Agriculture 36, 563-569.

Sánchez -Blanco MJ, Ferrández T, Morales MA, Morte A, Alarcon JJ. 2004 - Variations in water status, gas exchange, and growth in Rosmarinus officinalis plants infected with Glomus deserticola under drought conditions. Journal of Plant Physiology 161, 675-82.

Schellenbaum L, Muller J, Boller T, Wiemken A, Schüepp H. 1998 - Effects of drought on non mycorrhizal and mycorrhizal maize: changes in the pools of non -structural carbohydrates, in the activities of invertase and trehalase, and in the pools of amino acids and imino acids. New Phytologist 138, 59-66.

Schubert A, Wyss P, Wiemken A. 1992 - Occurrence of trehalose in vesicular-arbuscular mycorrhizal fungi and in mycorrhizal roots. Journal of Plant Physiology 140, 41-45.

Sheng M, Tang M, Chen H, Yang B, Zhang F, Huang Y. 2008 - Influence of arbuscular mycorrhizae on photosynthesis and water status of maize plants under salt stress. Mycorrhiza 18, 287-296.

Simpson D, Daft M. (1990) Spore production and mycorrhizal development in various tropical crop hosts infected with Glomus clarum. Plant and Soil 121, 171-178.

Smith FA, Grace EM, Smith SE. 2009 - More than a carbon economy: nutrient trade and ecological sustainability in facultative arbuscular mycorrhizal symbioses. New Phytologist 182, 347-358.

Subramanian KS, Charest C, Dwyer LM, Hamilton RI. 1995 - Arbuscular mycorrhiza and water relations in maize under drought stress at tasselling. New Phytologist 129, 643-650.

Subramanian KS, Charest C. 1999 - Acquisition of $\mathrm{N}$ by external hyphae of an arbuscular mycorrhizal fungus and its impact on physiological responses in maize under drought stressed and well-watered conditions. Mycorrhiza 9, 69-75.

Subramanian KS, Santhanakrishnan P, Balasubramanian P. 2006 - Responses of field grown tomato plants to arbuscular mycorrhizal fungal colonization under varying intensities of drought stress. Scientia Horticulturae 107, 245-253.

Suriyagoda LDB, Ryan MH, Renton M, Lambers H. 2014 - Plant responses to limited moisture and phosphorus availability: a meta-analysis. Advances in Agronomy 124, 143 -200. 
Symanczik SJ, Blaszkowski J, Chwat G, Boller T, Wiemken A, Al-Yahya'ei MN. 2014 - Three new species of arbuscular mycorrhizal fungi discovered at one location in a desert of Oman: Diversispora omaniana, Septoglomus nakheelum and Rhizophagus arabicus. Mycologia 106, 243-259.

Tarafdar JC, Rao AV. 1997 - Response of arid legumes to VAM fungal inoculation. Symbiosis 22, 265-274.

Valdenegro M, Barea JM and Azcon R. 2001 - Influence of arbuscular-mycorrhizal fungi, Rhizobium meliloti strains and PGPR inoculation on the growth of Medicago arborea used as model legume for re-vegetation and biological reactivation in a semi-arid mediterranean area. Plant Growth Regulators 34, 233-240.

Wang WX, Vinocur B, Altman A. 2003 - Plant responses to drought, salinity and extreme temperatures: towards genetic engineering for stress tolerance. Planta 218, 1-14.

Wright DP, Scholes JD, Read DJ. 1998 - Effects of VA mycorrhizal colonization on photosynthesis and biomass production of Trifolium repens L. Plant, Cell \& Environment 21, 209-216.

Wu BY, Hogetsu T, Isobe K, Ishii R. 2007 - Community structure of arbuscular mycorrhizal fungi in a primary successional volcanic desert on the southeast slope of Mount Fuji. Mycorrhiza 17, 495-506.

Wu Q, Zou Y, He X. 2011 - Differences of hyphal and soil phosphatase activities in droughtstressed mycorrhizal trifoliate orange (Poncirus trifoliata) seedlings. Scientia Horticulturae 129, 294-298.

Wu QS, He XH, Zou YN, Liu CY, Xiao J, Li Y. 2012 - Arbuscular mycorrhizas alter root system architecture of Citrus tangerine through regulating metabolism of endogenous polyamines. Plant Growth Regulators 68, 27-35.

Wu QS, Srivastava AK, Zou YN. 2013 - AMF induced tolerance to drought stress in citrus: a review. Scientia Horticulturae 164, 77-87.

Wu QS, Xia RX and Zou YN. 2006a - Reactive oxygen metabolism in mycorrhizal and nonmycorrhizal citrus (Poncirus trifoliata) seedlings subjected to water stress. Journal of Plant Physiology 163, 1101-1110.

Wu QS, Zou YN, Xia RN. 2006b - Effect of water stress and arbuscular mycorrhizal fungi on reactive oxygen metabolism and antioxidant production by citrus (Citrus tangerine) roots. European Journal of Soil Biology 42, 166-172.

Yang Y, Tang M, Sulpice R, Chen H, Tian S, Ban Y. 2014 - Arbuscular mycorrhizal fungi alter fractal dimension characteristics of Robinia pseudoacacia L. seedlings through regulating plant growth, leaf water status, photosynthesis, and nutrient concentration under drought stress. J Plant Growth Regulators 33, 612-625.

Zhu JK, Hasegawa PM, Bressan R. 1997 - Molecular aspects of osmotic stress in plants. Critical Reviews in Plant Sciences 16, 253-277.

Zhu X, Song F, Liu S, Liu T, Zhou X. 2012 - Arbuscular mycorrhiza improves photosynthesis and water status of Zea mays L. under drought stress. Plant, Soil and Environment 58, 186 -191.

Zhu X, Song F, Liu S. 2011a - Arbuscular mycorrhiza impacts on drought stress of maize plants by lipid peroxidation, proline content and activity of antioxidant system. Journal of Food, Agriculture and Environment 9, 583-587.

Zhu X, Song F, Xu H. 2010 - Influence of arbuscular mycorrhiza on lipid peroxidation and antioxidant enzyme activity of maize plants under temperature stress. Mycorrhiza 20, 325332.

Zhu X, Song FB, Liu S, Liu T. 2011b - Effects of arbuscular mycorrhizal fungus on photosynthesis and water status of maize under high temperature stress. Plant and Soil 346, 189-199.

Zoppellari F, Malusa E, Chitarra W, Lovisolo C, Spanna F, Bardi L. 2014 - Improvement of drought tolerance in maize (Zea mays L.) by selected rhizospheric microorganisms. Italian Journal of Agrometeorology 19, 5-18. 